DOI: 10.20472/IAC.2018.935.013

\author{
SASA DREZGIC \\ University of Rijeka Faculty of Economics, Croatia
}

\title{
SUBNATIONAL GOVERNMENT INVESTMENT AND DYNAMIC FISCAL RULES
}

\begin{abstract}
:
The paper tries to deal with issue how to increase local government investment finance without jeopardizing fiscal position of local government as well as overall macroeconomic stability. One of the key challenges is to resolve an everlasting conflict between central and subnational government tier related to different perspectives of each jurisdiction. Namely, central government level is more concerned for macroeconomic position and usually is more inclined to centralise debt management and limit borrowing powers of subnational government. On the other hand, subnational government utilizes borrowing for large local communal infrastructure needs but faces short-term perspective of political mandate, which demands control aimed for prevention of excessive borrowing. In addition, heterogeneity of local governments in terms of fiscal capacity and fiscal position makes general deficit sharing mechanisms as poor solution to intergovernmental fiscal management. General deficit sharing mechanisms usually base on fixed budgetary limits, which do not enable control for weak subnational government units and exert too high limitations for more progressive ones. Introduction of more precise dynamic fiscal rules, which account for specific fiscal standing of each local government and fiscal system, would provide incentive for more productive borrowing policies. Such mechanism overcomes short-term financing perspective that comes from short-term political horizon and mid-term focus of budgetary documentation. The results of the research brings clear policy recommendations. It is possible to replace existing deficit sharing mechanisms by more productive and efficient dynamic system. This would bring not just improved debt management control but provide incentive for more efficient borrowing.
\end{abstract}

\section{Keywords:}

subnational government investment, fiscal rules, borrowing, dynamic fiscal rules, deficit sharing

JEL Classification: E62, H60, H70 